\title{
PELATIHAN URBAN FARMING SEBAGAI SOLUSI RUANG TERBUKA HIJAU DI LORONG SIDODADI MEDAN HELVETIA
}

\author{
Putri Lynna Adelinna Luthan" ${ }^{*}$, Yogi Nikman', Hasanatun Nisa Hasibuan², Jaka Prima \\ Albertus Malau ${ }^{1}$
}

\author{
${ }^{1}$ Jurusan Pendidikan Teknik Bangunan, Fakultas Teknik, Universitas Negeri Medan, Medan, Indonesia \\ ${ }^{2}$ Jurusan Biologi, Fakultas Matematika dan Ilmu Pengetahuan Alam, Universitas Negeri Medan, Medan, Indonesia \\ *Penulis Korespodensi: putri.lynna@unimed.ac.id
}

\begin{abstract}
Abstrak
Kota Medan dengan pertumbuhan penduduk yang tinggi ditambah dengan pembangunan pesat seringkali mengubah konfigurasi alami lahan sehingga merugikan keberadaan Ruang Terbuka Hijau (RTH). RTH Kota Medan yang ada saat ini baru 5,6 \% atau 14,84 $\mathrm{km}^{2}$. lorong Sidodadi Kecamatan Medan Helvetia dipilih karena kawasan tersebut merupakan pemukiman padat yang kurang akan RTH dan memiliki kelompok ibu rumah tangga non-produktif. Kebijakan yang dapat dilakukan untuk memulihkan kembali kondisi lingkungan hidup dan mengatasi permasalahan RTH di lorong Sidodadi yaitu dengan menerapkan program urban farming secara vertikultur dengan melibatkan ibu rumah tangga non-produktif. Metode pelaksanaan pelatihan urban farming dengan vertikultur dilakukan dengan 5 tahapan, yaitu tahap persiapan, sosialisasi, pelatihan, pendampingan dan evaluasi. Hasil kegiatan pelatihan urban farming di lorong Sidodadi mendapat respon yang positif dan antusiasme kelompok sasaran. Seluruh peserta merasakan banyak manfaat dari segi estetika, kenyamanan thermal dan psikis, kesehatan serta ekonomi dan mengakui bahwa lorong Sidodadi terlihat lebih asri dari sebelumnya. Banyak warga non-peserta yang mulai tertarik untuk ikut serta menerapkan program urban farming di rumah mereka sendiri. Warga yang telah menerapkan program tidak lagi membeli beberapa jenis sayur ke pasar. Masalah yang timbul dalam kegiatan ini adalah hama tikus dan aktivitas anak-anak di sekitar lingkungan.
\end{abstract}

Kata kunci: Permukiman Padat, Ruang Terbuka Hijau, Vertikultur Urban Farming.

\begin{abstract}
Medan City with high population growth coupled with rapid development often change the natural configuration of the land to the detriment of the existence of Green Open Space (RTH). RTH of Medan City is currently only $5.6 \%$ or $14.84 \mathrm{~km} 2$. Lorong Sidodadi in Medan Helvetia subdistrict is chosen because the area is a densely populated settlements that lacks of Green Spaces and has a group of nonproductive housewives. Policies that can be done to restore environmental conditions and overcome the Green Spaces problem in Sidodadi is by implementing verticulture urban farming program involving non-productive housewife. The method of implementation of urban farming with verticulture training done with 5 stages, namely the preparation stage, socialization, training, mentoring and evaluation. The results of the urban farming training activities in Lorong Sidodadi received a positive response and the enthusiasm of the target group. All participants felt a lot of benefits in terms of aesthetics, thermal and psychic comfort, health and economy and admitted that the aisle Sidodadi looks more beautiful than ever. Many non-participating citizens are getting interested to participate in implementing urban farming programs in their own homes. Residents who have implemented the program no longer buy some types of vegetables to market. Problems that arise in this activity are rat pests and children activity around the environment.
\end{abstract}

Keywords : Densely Populated Settlements, Green Open Space, Verticulture Urban Farming.

\section{PENDAHULUAN}

Kota Medan, sebagai kota ketiga terbesar di Indonesia, merupakan kota metropolitan baru yang mengalami perkembangan sangat pesat sebagai koridor pertumbuhan ekonomi nasional bagian barat dan sebagai kawasan strategis yang menjadi pintu gerbang bagi para wisatawan untuk menuju berbagai objek wisata. Kota Medan dengan populasi 2.191.140 jiwa dan kepadatan penduduk 8.268 jiwa $/ \mathrm{km}^{2}$ (BPS Provinsi Sumatra Utara, 2015), memiliki potensi kerusakan dan ketidakseimbangan lingkungan yang amat besar.

Pertumbuhan penduduk yang tinggi ditambah dengan pembangunan yang pesat sebagai upaya pemenuhan 
kebutuhan, terutama untuk permukiman, seringkali mengubah konfigurasi alami lahan/bentang alam perkotaan, juga menyita lahan-lahan tersebut dan berbagai bentukan ruang terbuka lainnya. Kedua hal ini umumnya merugikan keberadaan Ruang Terbuka Hijau (RTH) yang sering dianggap sebagai lahan cadangan dan tidak ekonomis. Menurunnya kuantitas dan kualitas ruang terbuka publik yang ada di perkotaan, baik berupa Ruang Terbuka Hijau (RTH) dan ruang terbuka nonhijau telah mengakibatkan menurunnya kualitas lingkungan perkotaan seperti seringnya terjadi banjir di perkotaan, tingginya polusi udara dan meningkatnya kerawanan sosial (kriminalitas dan krisis sosial) serta menurunnya produktivitas masyarakat akibat stress karena terbatasnya ruang publik yang tersedia untuk interaksi sosial (Illiyin dan Idajati, 2015).

Menurut Peraturan Menteri Pekerjaan Umum Nomor 05/PRT/M/2008, Setiap kota harus memiliki minimal $30 \%$ Ruang Terbuka Hijau (RTH) dan kriteria RTH tersebut seharusnya ditambah, dengan mempertimbangkan pemilihan jenis-jenis tanaman yang mempunyai fungsi ganda, yaitu tanaman yang dapat menghasilkan $\mathrm{O}_{2}$ sekaligus mereduksi CO. Kadis Kebersihan dan Pertamanan Kota Medan M Husni mengungkapkan, RTH Kota Medan yang ada saat ini baru 5,6 \% atau 14,84 $\mathrm{km}^{2}$ (Inilahmedan.com, 2017). Data tersebut menunjukkan ketidakseimbangan antara infrastruktur yang dibangun dengan pemenuhan kebutuhan ruang terbuka hijau.

Kebijakan yang dapat dilakukan untuk memulihkan kembali kondisi lingkungan hidup dan mengatasi permasalahan RTH di kota Medan yaitu dengan menerapkan program urban farming. Enciety (2011) dalam Hadi (2016:137) menyatakan Urban farming adalah kegiatan memanfaatkan ruang-ruang terbuka yang tidak produktif seperti lahan pekarangan atau lahan kosong yang tidak terpakai dan sebagainya, menjadi lahan perkebunan produktif, sehingga dapat menjadi kegiatan alternatif masyarakat kota untuk meningkatkan kualitas dan kuantitas ruang terbuka hijau. Selain menambah proporsi ruang terbuka hijau, penerapan urban farming berdampak langsung terhadap ekonomi, sosial, penggunaan energi, jejak karbon, polusi (udara, tanah dan suara), serta peningkatan ketersediaan dan kualitas bahan pangan (Alaimo et al., 2008).

Penerapan urban farming ini dapat dilakukan dengan menggunakan teknologi hijau sederhana berupa teknik vertikultur yang hemat lahan, mengingat lahan di perkotaan yang sangat terbatas. Vertikultur adalah sistem tanam di dalam pot yang disusun/ dirakit horizontal dan vertikal atau bertingkat pada lahan terbatas atau halaman rumah (Nurmawati dan Kadarwati, 2016). Menurut Damastuti (1996), kelebihan vertikultur antara lain: efisiensi penggunaan lahan, menghemat air, menghemat pupuk dan pestisida, serta mudah dalam pemeliharaan tanaman. Teknik vertikultur ini dianggap sebagai solusi yang aman, efisien, mudah dan akan memberikan dampak yang sangat besar apabila dilakukan oleh penduduk kota Medan secara tersistematis, terstruktur dan massif.

Lorong Sidodadi adalah salah satu nama jalan di kelurahan Sei Sikambing CII, kecamatan Medan Helvetia, kota Medan, Sumatra Utara. Wilayah ini terletak cukup dekat dengan pusat kota Medan. Kondisi wilayahnya padat dengan pemukiman penduduk dan didominasi oleh rumah menengah ke bawah dengan masyarakat berpenghasilan rendah yang tidak menerapkan konsep keseimbangan bangunan dan lahan hijau. Wilayah lorong Sidodadi juga minim akan ruang terbuka hijau (RTH). Lahan kosong yang ada sudah dimanfaatkan untuk pembangunan rumah tinggal, ataupun sebagai lahan parkir yang diberi perkerasan beton.

Sekitar 23\% dari jumlah penduduk kawasan lorong Sidodadi adalah Ibu Rumah Tangga (IRT) nonproduktif atau tidak berpenghasilan, berdasarkan hasil observasi dan wawancara yang kami lakukan dengan Kepala Lingkungan (Kepling). Indikator "ibu-ibu" yang kami tetapkan adalah wanita berusia 28 tahun ke atas dan sudah mempunyai suami. Beberapa dari IRT tersebut merupakan keluarga yang berpenghasilan rendah, atau hidup pas-pasan.

Melihat keadaan tersebut, kawasan ini berpotensi untuk diterapkan konsep urban farming dengan vertikultur, dengan mengajak ibu rumah tangga non-produktif sebagai kelompok sasaran, sehingga mampu menularkan antusiasme dalam menerapkan konsep urban farming pada kehidupan sehari-hari, yang akan menghijaukan lingkungan Sidodadi, menghasilkan sayur yang sehat dan bergizi, serta meningkatkan perekonomian warga.

\section{BAHAN DAN METODE}

Metode pelaksanaan program urban farming dengan vertikultur di lorong Sidodadi Kecamatan Medan Helvetia dilakukan dengan 5 tahapan, yaitu :

a. Tahap Persiapan

yaitu meliputi penentuan lokasi pelatihan, perhitungan jumlah peserta, penjadwalan kegiatan lanjutan, penyiapan materi presentasi, desain modul, alat, bahan, transport dan anggaran biaya awal.

b. Tahap Sosialisasi

Dengan pemberian materi pengenalan urban farming, gambaran contoh penerapan dan medianya. Peserta pelatihan dan warga lain yang ikut melihat juga diberikan buku pedoman urban farming yang berisi teori, manfaat program dan langkah penerapan secara rinci, dari mulai pemilihan bibit sampai pembuatan modul/ wadah tanam.

c. Tahap Pelatihan

Peserta kelompok sasaran diberi pelatihan yang berisi 5 materi, yaitu penentuan dan pemilihan bibit, pemilihan jenis modul tanam, pengenalan bagian rangka modul, cara penanaman dan cara perawatan. 
d. Tahap Pendampingan

Tim akan memperhatikan cara pelaksanaan program yang dilakukan kelompok sasaran, berdiskusi bersama untuk mengembangkan ide serta kreativitas peserta, dan penguatan keterampilan juga pemanfaatan hasil program.

e. Tahap Evaluasi

Merupakan tahapan akhir dari program dimana tim peneliti akan meninjau dan menilai hasil dari program yang telah dilaksanakan kelompok sasaran serta melakukan wawancara kepada beberapa peserta mengenai pendapat program, kebermanfaatan program, kendala yang dihadapi serta rencana ke depan untuk mengembangkan program urban farming. Indikator keberhasilan program yaitu banyak warga yang mulai menanam di rumahnya, peningkatan jumlah warga yang menerapkan program, pengurangan pembelian sayur-sayuran dan peningkatan pengetahuan warga mengenai konsep urban farming.

\section{HASIL DAN PEMBAHASAN}

Pengabdian masyarakat di lorong Sidodadi Kecamatan Medan Helvetia dilakukan karena kawasan tersebut merupakan pemukiman padat yang kurang akan RTH dan memiliki kelompok ibu rumah tangga yang tidak produktif. Pengabdian dilakukan dalam bentuk pelatihan urban farming kepada kelompok sasaran yaitu ibu rumah tangga non-produktif. Pembuatan modulmodul taman vertikal dimaksudkan sebagai wadah menanam warga, yang tidak memiliki lahan ataupun terbatas.

Program yang dilaksanakan mendapat respon positif dari kelompok sasaran, warga sekitar dan kepala lingkungan. Hal tersebut terlihat dari antusiasme warga dan kelompok sasaran untuk lebih mengenal dan memahami urban farming saat tahap sosialisasi (Gambar 1) dan pelatihan (Gambar 2).

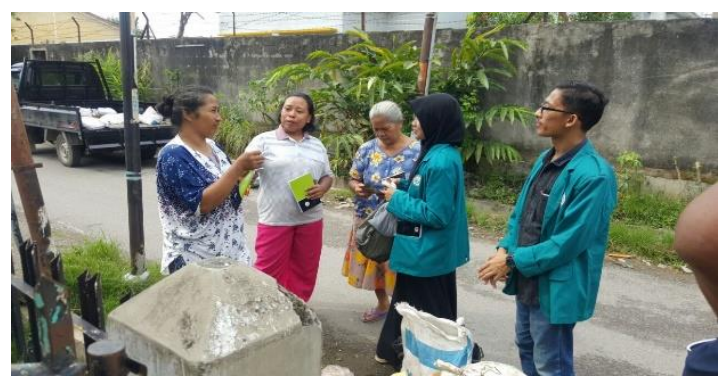

Gambar 1. Tim peneliti berdiskusi dengan ibu-ibu rumah tangga mengenai progam (dok. Pribadi).

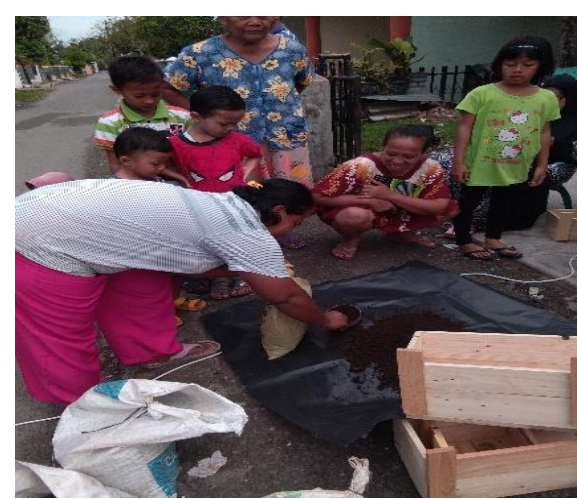

Gambar 2. Warga dan peserta pelatihan tampak antusias saat sedang mencampurkan tanah, pupuk dan sekam padi (dok. Pribadi).

Untuk pembuatan rangka modul tanam, dilakukan di Workshop Kayu Fakultas Teknik, Universitas Negeri Medan yang melibatkan tim dan seorang tukang kayu profesional. Pembuatan rangka modul dibuat per bagian, untuk mempermudah pengangkutan. Bagianbagian modul dibuat dan diolah terlebih dahulu di Workshop, lalu kemudian dirakit di lapangan.

Perakitan modul di lapangan dibantu oleh beberapa orang warga, yang kebanyakan merupakan suami atau anak laki-laki dari ibu rumah tangga yang menjadi peserta pelatihan. Contoh modul tanam terpasang dapat dilihat seperti Gambar 3.

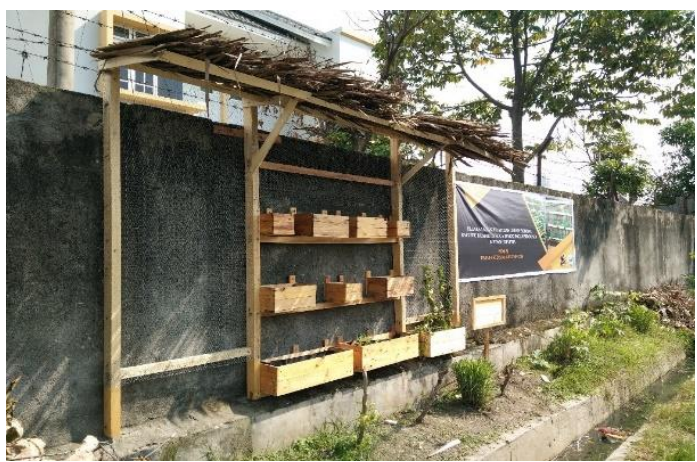

Gambar 3. Contoh modul vertikal dengan pot dan kawat jaring (dok. Pribadi).

Pada saat pelatihan dan pendampingan, tim memberikan beberapa bibit tanaman kepada kelompok sasaran, yang diantaranya adalah bibit bayam, bibit cabai rawit, bibit kacang panjang, bibit kangkung, bibit sawi, bibit seledri dan bibit tomat. Setelah hampir 3 bulan pelaksanaan program, beberapa tanaman mulai menampakkan hasil, dan ada beberapa tumbuhan yang sudah mulai berbuah seperti tomat (Gambar 4), ataupun sudah bisa dipanen seperti kangkung dan sawi. 


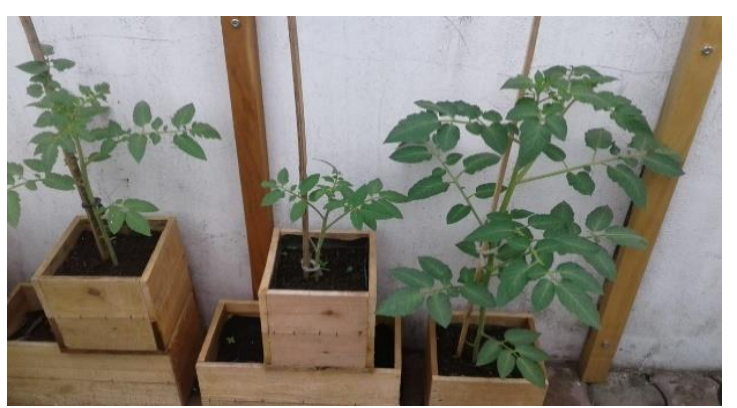

Gambar 4. Tumbuhan tomat yang ditanam pada pot mulai meninggi (dok. Pribadi).

Dari hasil wawancara yang dilakukan tim kepada beberapa peserta kegiatan, dapat disimpulkan bahwa mereka menyambut baik program yang kami berikan dan berdampak positif. Hal ini juga tergambar saat pelatihan, dimana peserta sangat semangat dan antusias dalam menyiapkan media tanam dan memasukkan benih. Selain itu, kelompok sasaran mengakui bahwa kegiatan ini membawa banyak manfaat bagi kesehatan dan kenyaman lingkungan. Kemudahan juga dirasakan, dimana kelompok sasaran tidak kesulitan untuk mencari beberapa jenis sayur di pasar, karena dapat memetik langsung dari tanaman pangan yang mereka rawat. Ada pula peserta yang membagikan hasil tanamannya kepada tetangga sekitar, sehingga warga lain juga ikut tertarik dan ingin menerapkan program urban farming di rumahnya sendiri. Hal ini terlihat dari beberapa orang warga non-peserta yang datang kepada tim untuk meminta bibit dan diajari cara menanam.

Peserta kegiatan juga menerangkan bahwa ada beberapa kendala yang cukup menghambat dalam melaksanakan kegiatan urban farming ini, yaitu faktor hama dan aktivitas anak-anak di sekitar lingkungan. Hama yang muncul disini adalah tikus kecil yang sering memakan kecambah serta tanaman, sehingga tanaman gagal tumbuh dan mati. Aktivitas anak kecil yang seringkali datang dan mencabut beberapa tanaman juga menghambat produktivitas tanaman pangan.

Rencana peserta pelatihan di masa yang akan datang adalah terus mengembangkan tanaman yang telah dimiliki dan beberapa diantaranya berniat menjual hasil panen atau berwirausaha di bidang urban farming.

Harapan masyarakat kelompok sasaran mengenai keberlanjutan program ini ke depannya adalah agar program ini terus dilanjutkan dan dipasang modul tanam lebih banyak lagi agar lorong Sidodadi terlihat lebih cantik dan asri serta bermanfaat lebih bagi masyarakat sekitar.

\section{KESIMPULAN}

Berdasarkan hasil kegiatan PKM-M pelatihan keterampilan urban farming bagi ibu rumah tangga nonproduktif yang telah dilaksanakan, maka didapat kesimpulan sebagai berikut:

- Pada saat sosialisasi dan pelatihan dilakukan, antusiasme masyarakat Sidodadi sudah mulai terlihat, dari mulai bertanya secara detail tentang konsep urban farming, sampai kepada aktivitas penanaman yang dilakukan dengan semangat. Seluruh peserta pelatihan turut aktif dalam program ini dan merasakan banyak manfaat dari segi estetika, kenyamanan thermal dan psikis, kesehatan serta ekonomi.

- Banyak warga non-peserta yang mulai tertarik untuk ikut serta menerapkan program urban farming di rumah mereka sendiri.

- Banyak warga yang mengakui bahwa lorong Sidodadi terlihat lebih asri dari sebelumnya, dan udara sekitar lebih nyaman karena banyak tumbuhtumbuhan.

- Masalah yang timbul dalam kegiatan ini adalah hama tikus dan aktivitas anak-anak di sekitar lingkungan.

- Rencana dan harapan masyarakat ke depannya adalah agar program ini dapat terus berlanjut dan diterapkan di rumah serta lingkungan yang lain.

Konsep urban farming memang bukan hal yang baru dalam dunia pertanian, namun di kota Medan sendiri, teknik berkebun dengan cara ini masih jarang diterapkan. Padahal dengan dana yang terbatas, urban farming dengan teknik vertikultur dapat menjadi pilihan alternatif yang murah dan mudah. Apabila diterapkan dengan baik, konsep verticulture urban farming ini tentu dapat mengentaskan permasalahan RTH, dampak polusi udara dan kemandirian pangan. Penerapan tersebut tentunya harus didukung dengan sumber daya manusia dan teknologi yang mumpuni. Serta tidak lepas dari dukungan masyarakat, pemerintah, lembaga penelitian, perguruan tinggi dan institusi terkait, yang diharapkan dapat memberikan konstribusi yang positif.

\section{UCAPAN TERIMA KASIH}

Terima kasih disampaikan kepada Direktorat Jendral Belmawa melalui Program Kreativitas Mahasiswa yang telah mendanai kegiatan pengabdian masyarakat ini. Tidak lupa pula, kami ucapkan terimakasih kepada Dosen pendamping kami yaitu ibu Dr. Ir. Putri Lynna A. Luthan, M.Sc., IPM. yang telah membimbing kami sejauh ini, serta Wakil Dekan III FT, Wakil Rektor III Unimed dan staff yang telah banyak membantu.

\section{DAFTAR PUSTAKA}

Alaimo, K., Packnett, E., Miles, R., Kruger dan D. (2008). Fruit and Vegetable Intake among Urban Community Gardeners. Journal of Nutrition Education and Behavior, 40 (2), p. 94.

BPS Provinsi Sumatra Utara. (2015). Luas Wilayah, Jumlah Penduduk dan Kepadatan Penduduk Menurut Kabupaten/ Kota. November. BPS Sumatra Utara. Medan.

Damastuti, A. P. (1996). Pertanian Sistem Vertikultur. Wacana Bank Indonesia: Jakarta.

Hadi, P. (2016). Konsep Prototype Integrated Verticulture Aquaponic City Farming Di Kampung Batik Surakarta. Seminar Nasional Dies Natalis XXXIII Universitas Islam Batik 
Surakarta (pp. 131-141). Surakarta, Indonesia, Universitas Islam Batik Surakarta.

Illiyin, D. F. dan H. Idajati. (2015). Faktor-Faktor Yang Mempengaruhi Masyarakat Dalam Penggunaan Ruang Terbuka Publik Sebagai Fungsi Sosial Di GOR Delta Sidoarjo Berdasarkan Preferensi Masyarakat. Jurnal Teknik ITS, 4(2), 114-118.

Inilahmedan.com. 2017. Ruang Terbuka Hijau Kota Medan Baru 5,6 Persen. https://www.inilahmedan.com/2017/04/ruangterbuka-hijau-kota-medan-baru-56.html. 3 Juli 2018 (13:07).

Nurmawati dan S. Kadarwati. (2016). Vertikultur Media Pralon Sebagai Upaya Memenuhi Kemandirian Pangan di Wilayah Peri Urban Kota Semarang. Jurnal Pendidikan Sains, 4(2), 19-25.

Peraturan Menteri Pekerjaan Umum Nomor 05/PRT/M/2008. Pedoman Penyediaan dan Pemanfaatan Ruang Terbuka Hijau Di Kawasan Perkotaan. Dirjen Tata Ruang-Departemen PU. Jakarta. 